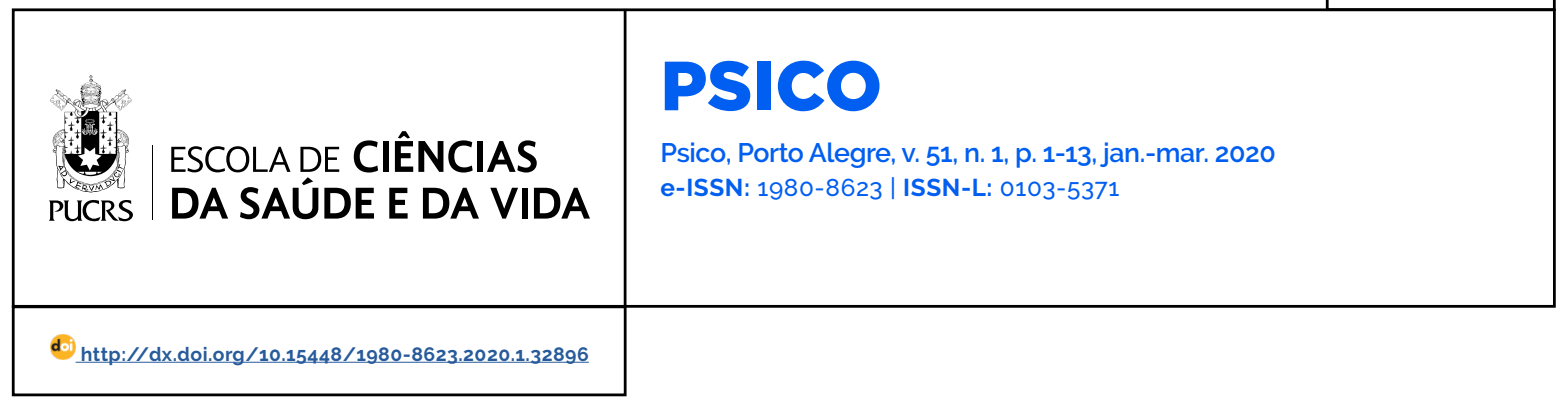

REVISÃO

\title{
Pobreza, instituições e segurança: perspectivas de familiares de adolescentes assassinados no Ceará
}

\author{
Poverty, institutions and security: perspectives of adolescents' families murdered in Ceará \\ Pobreza, instituciones y seguridad: perspectivas de familiares de adolescentes \\ asesinados en el Ceará
}

\author{
João Paulo Pereira \\ Barros $^{1}$ \\ orcid.org/0000-0001-7680-576X \\ joaopaulobarros07@gmail.com
}

\section{James Ferreira Moura \\ Júnior ${ }^{2}$ \\ orcid.org/0000-0003-0595-5861 \\ james.mourajr@unilab.edu.br}

\section{Damião Soares de \\ Almeida Segundo ${ }^{1}$}

orcid.org/0000-0003-2407-0583

damiao_soares@hotmail.com

\section{Rodrigo Bezerra \\ Saraiva ${ }^{1}$}

orcid.org/0000-0002-7748-5187 rodrigobezerrasaraiva@gmail.com

\section{Marcus Giovani Ribeiro \\ Moreira $^{1}$}

orcid.org/0000-0002-3622-3498 marcusgigio@hotmail.com

Recebido em: 2/1/2019. Aprovado em: 10/9/2019. Publicado em: XX XXX. 2020.

\section{(c) (i)}

Artigo está licenciado sob forma de uma licença Creative Commons Atribuição 4.0 Internacional.
Resumo: Objetivou-se, por meio de levantamento, analisar as implicações da pobreza na segurança e no acesso institucional de familiares de jovens assassinados no Ceará. Participaram do estudo 263 familiares, os jovens eram homens $(97,7 \%)$ e negros $(70,3 \%)$ com idades entre 11 e 19 anos ( $M=16,6 ; \mathrm{DP}=1,34)$. As análises desenvolvidas foram descritivas e comparativas (qui-quadrado e ANOVA). Os participantes apresentaram baixa confiança institucional, mas o grupo mais pobre apresentou significativamente menos confiança na polícia $(\chi 2=30,36$; $p<$ 0,001 ). O grupo mais pobre indicou significativamente mais as batidas policiais representando perigo no bairro $(\chi 2=5.5 ; \mathrm{p}<0,01)$ e mais a percepção da presença policial como intimidadora $(F=34,487 ; p<0,001)$. Não houve diferenças significativas em relação aos motivos da violência no bairro. Observa-se a existência de uma gestão da morte vinculada a uma estrutura de Estado e de sociedade que criminaliza a pobreza.

Palavras-chave: homicídio, adolescentes, pobreza, instituições, segurança.

Abstract: This study aims was to analyze the implications of the poverty condition on security and access to institutions in the perceptions of adolescents' families members and young people murdered in Ceará. 263 families of adolescent victims of homicide participated in the study aged between 11 and $19(M=16.6, S D=1.34)$, blacks (70.3\%), males (97.7\%) and family income of one to two minimum wages $(64.1 \%)$. A survey was conducted, the questions related to territorial security, institutional relations and multidimensional poverty. The analyzes were descriptive and comparative (chi-square and ANOVA). The results show that families in situations of greater poverty have less access to institutions, assess their territories as more dangerous and suffer more violence. It is observed the existence of a death management linked to a structure of State and society that criminalizes poverty. Keywords: homicide, adolescents, poverty, institutions, security.

Resumen: Se objetivó analizar las implicaciones de la condición de pobreza en la seguridad y el acceso a las instituciones para miembros de familias de adolescentes y jóvenes asesinados en Ceará. En el estudio participaron 263 familias de adolescentes víctimas de homicidio, con edades entre 11 y 19 años ( $M$ $=16,6, \mathrm{SD}=1,34)$, negros $(70,3 \%)$, hombres $(97,7 \%)$ e ingresos familiares de uno a dos salarios mínimos $(64,1 \%)$. Se realizó una encuesta, las cuestiones aplicadas se refirieron a la seguridad territorial, las relaciones institucionales y la pobreza multidimensional. Los análisis fueron descriptivos y comparativos (chi-cuadrado y ANOVA). Los resultados apuntan que las familias en situaciones de pobreza más intensa tienen menos acceso a las instituciones, evalúan sus territorios como más peligrosos y sufren más violencia. Se observa la existencia de una gestión de la muerte vinculada a una estructura de Estado y sociedad que criminaliza la pobreza. Palabras clave: homicidio, adolescentes, pobreza, instituciones, seguridad. 
No ano de 2016, o Brasil registrou 62.517 casos de homicídio, a maior quantidade em sua história. Nesse contexto, os jovens têm sido as principais vitimas. Nesse mesmo ano, foram registrados 33.590 casos de homicídio para a população de 15 e 19 anos, configurando o homicidio como a principal causa externa de morte desse segmento populacional (Cerqueira et al., 2018). Particularmente, o estado do Ceará apresentou, em 2014, o maior Índice de Homicidio na Adolescência (IHA) entre os estados brasileiros (8,71/mil) (Melo \& Cano, 2017). E, em 2017, ocorreram 981 mortes de crianças e adolescentes, um aumento de quase 59\% em relação às 655 do ano anterior (Assembleia Legislativa do Estado do Ceará, 2018). Este artigo tem como objetivo analisar as implicações da pobreza na segurança e no acesso institucional de familiares de jovens assassinados no Ceará. É importante salientar que este estudo foi desenvolvido de forma representativa com as famílias de jovens assassinados, diferenciando dos métodos de seleção por conveniência nas pesquisas em Psicologia e do local de realização em um estado no Nordeste do Brasil (Joly, Berberian, Andrade, \& Teixeira, 2010).

Esses indicadores de homicidios expõem a gravidade do problema, mas não revelam os distintos cruzamentos de desigualdade e exclusão aos quais os adolescentes vítimas de homicídio e seus familiares estão submetidos. Alguns estudos apontam que o risco de morte por homicidio é influenciado por idade, raça e nivel socioeconômico (e.g. Assembleia Legislativa do Estado do Ceará, 2017; Cerqueira et al., 2017. 2018; Melo \& Cano, 2017). Por exemplo, na cidade de Fortaleza, análises epidemiológicas espaciais demonstraram que os casos de homicidios de adolescentes se concentram em bairros e assentamentos marcados pela pobreza. No ano de 2017, 48,6\% do total de homicidios de jovens ocorreram em 10 dos 119 bairros da cidade (Assembleia Legislativa do Estado do Ceará, 2018). Ou seja, a distribuição territorial dos homicídios também indica quais são as pessoas predominantemente atingidas por essa forma de violência; sujeitos os quais o Estado alcança, quase que exclusivamente, por meio de suas instituições de repressão e punição.

Nesse sentido, a condição de pobreza ajuda na compreensão do contexto de produção desses homicídios. Isso porque, existe uma estrutura macrossocial pautada na acumulação e na distribuição desigual das riquezas que criminalizam essas pessoas por sua condição social e mantém o status quo (Moura Jr., \& Ximenes, 2016). Historicamente, um conjunto de valores e atribuições perversas e depreciativas são dirigidas às pessoas em situação de pobreza (Rego \& Pinzani, 2013). Entende-se que o poder midiático pode ser um dos possiveis promotores dessas crenças, que são coloniais, mas também contemporâneas (Accorsi, Scarparo, \& Guareschi, 2012). Compreende-se que há, então, uma série de papéis sociais ligados a essa identidade social estigmatizada de pobre, como vagabundo, criminoso, conformado, culpado por sua situação, entre outros (Moura Jr. \& Ximenes, 2016).

A pobreza, em uma perspectiva multidimensional, não é apenas a pauperização monetária, mas um conjunto de privações que prejudicam o exercício da autonomia e da liberdade devido à restrição de acesso à educação, emprego, renda, benefícios sociais, segurança, justiça, entre outros (Sen, 2010). Nessa perspectiva, entende-se como necessário ampliar a compreensão da pobreza também para a falta de acesso e do estabelecimento de políticas públicas efetivas. De acordo com o relatório Cada Vida Importa da Assembleia Legislativa do Estado do Ceará (Assembleia Legislativa do Estado do Ceará, 2017), essas politicas podem funcionar como fator de proteção quando alcançam a população em situação de pobreza. No entanto, esse acesso pode ser dificultado pela reprodução de preconceitos contra os usuários e as usuárias dos serviços por parte dos profissionais (Freitas \& Guareschi, 2014).

Dessa forma, somando esse processo de violência, estigmatização da pobreza e dificuldade de acesso a políticas públicas, observa-se que há um Estado que legitima a exclusão da juventude pobre. Por exemplo, Scisleski, Caetano 
e Galeano (2015) afirmam que, apesar de a lei estabelecer formalmente a proteção de crianças e adolescentes, em muitas situações eles são tratados como os adultos, por exemplo, no cumprimento de medidas socioeducativas com restrição de liberdade (e.g., uso de algemas, raspagem dos cabelos, encarceramento em celas, truculência por parte dos agentes de segurança). Assim, o Estado se faz impolítico ao atuar em relação a essa população, prioritariamente, por meio de ações de segurança voltadas ao conflito ao invés de dar condições adequadas de vida.

Para Bezerra e Carvalho (2015), a construção de discursos negativos sobre as periferias e os seus habitantes se vinculam ao fortalecimento desse Estado securitário centrado no "combate" à insegurança social, em detrimento do Estado protetivo. Tal dinâmica torna-se ainda mais grave quando o aparato de segurança pública que serviria para proteger atua como um mecanismo de repressão e de controle das classes mais pobres (Zaccone, 2015). No Brasil, entre 2009 e 2016, 21.892 pessoas perderam suas vidas em ações policiais e desde 2013 a quantidade de pessoas vitimadas por homicidio em ações policiais não param de subir (Cerqueira et al., 2017). Essas mortes, no entanto, são vistas por parte da população como apenas uma causalidade necessária à instauração da ordem, desumanizando as vítimas sob a égide da máxima "bandido bom é bandido morto", dando a entender que tais vidas não são nem mesmo concebidas como vidas em si, sendo elas, como afirma Butler (2015), vidas não passíveis de luto.

Nesse sentido, Wacquant (2012) discute as relações entre o bem-estar social e as politicas penais. Esse contexto se relaciona com o neoliberalismo, que aumenta o Estado penal e reduz o Estado social, o papel da assistência é deslocado e adicionado ao emprego da polícia, dos tribunais e da prisão. O desamparo institucional aos pobres se vincula à uma dupla regulação da pobreza pelo conjunto da ação da assistência e da burocracia penal. Ademais, Coimbra (2001) aponta o reconhecimento das pessoas em situação de pobreza como uma "classe perigosa" pela associação com o crime e a periculosidade. Barros e Benício (2017) consideram que essa associação histórica atua na produção de "sujeitos matáveis", como a figura do "jovem envolvido". O estereótipo do "bandido" que se personaliza na imagem do jovem negro, morador da favela, cooptado ou não pelo tráfico de drogas, e que possui um modo de se vestir com bonés, cordões etc.

Dessa forma, as familias desses jovens assassinados inserem-se nessa conjuntura de discriminação, violência e falta de proteção. Apesar do sofrimento já causado pelo assassinato de um adolescente, a condição de pobreza persiste e o Estado mantém a sua estrutura de violência contra essas familias. Portanto, este artigo tem como objetivo analisar as implicações da pobreza na segurança e no acesso institucional de familiares de jovens assassinados no Ceará.

\section{Método}

\section{Participantes}

Participaram 263 responsáveis (mães, avós e tias) por adolescentes assassinados no estado do Ceará em 2015 com idades entre 11 e 19 anos $(M=16,6 ; D P=1,34)$, negros $(70,3 \%)$ e do sexo masculino (97,7\%). Em sua maioria com renda familiar de um a dois salários mínimos (64,1\%) e cujo principal responsável possuía apenas o Ensino Fundamental incompleto (49\%). Os dados referem-se às sete cidades com maior ocorrência de homicídio de jovens, são elas: Fortaleza, Sobral, Juazeiro do Norte, Caucaia, Maracanaú, Horizonte e Eusébio. É importante salientar que essa amostra foi representativa das familias com adolescentes assassinados neste ano de 2015 no Ceará, diferenciando das amostras por conveniência desenvolvidas em pesquisas na Psicologia (Damásio, 2013).

\section{Instrumentos}

Os microdados analisados neste estudo foram produzidos a partir de um questionário criado pelo Comitê Cearense pela Prevenção de Homicídios na Adolescência (CCPHA) vinculado à Assembleia Legislativa do Estado do Ceará, o qual possuía 139 
questões que abordavam aspectos individuais, familiares, comunitários e institucionais. Para atingir os objetivos propostos neste artigo, foram utilizadas apenas as questões referentes à segurança territorial, à relação institucional e à pobreza multidimensional das familias que tiveram vítimas de homicídio.

As perguntas relacionadas à segurança territorial foram: 1) "Você considera o bairro perigoso?" respondido com sim ou não; 2) "Para você, o que representa perigo no bairro?", respondido por meio das opções tráfico de drogas, batidas policiais, assaltos e roubos, tiroteios, assassinatos e outros motivos; 3) "Você considera o bairro violento?" respondido com sim ou não; 4) "Para você, qual o principal motivo das situações de violência no bairro onde o(a) adolescente morava?", respondido por meio das opções tráfico de drogas, conflito entre gangues, conflitos entre territórios, conflitos passionais, conflitos entre vizinhos, conflito com agentes públicos e outros motivos; e 5) "Como você avalia a presença do policiamento no bairro?", respondido por escala likert de três pontos (intimidadora, indiferente, protetora).

As questões referentes à relação institucional foram: 1) "Em qual(is) dessas instâncias você confia?", respondido por meio das opções justiça, vizinhança, amigos, conselho tutelar, instituições religiosas, polícia, escola, programas de rádio e televisão, familia e nenhuma; e 2) "Indique e avalie quais instituições a familia buscou após a morte do/da adolescente?", respondido pela indicação das opções conselho tutelar, delegacia de polícia, defensoria pública, juizado da infância e da juventude, ministério público, organização da sociedade civil, hospital, instituto médico legal ou outras.

Por fim, foram utilizados 15 indicadores relacionados à pobreza multidimensional (por exemplo, renda per capita, acesso à água e energia e nivel de escolaridade), abarcando cinco dimensões (educação, trabalho e beneficios sociais, condições de moradia, bem-estar econômico e segurança) para a construção de um índice de Pobreza Multidimensional (IPM) (Alkire \& Foster, 2011). Esse formato de medição tem a perspectiva gradativa da pobreza, sendo uma medida que capta com mais profundidade e complexidade esse fenômeno de privação (Avila, Bagolin, \& Comin, 2012; Feres \& Villatoro, 2013; Moura Jr, Cidade, Ximenes, \& Sarriera, 2014; Ximenes, Moura Júnior, Cruz, Silva, \& Sarriera, 2016).

\section{Procedimentos}

A Assembleia Legislativa do Estado do Ceará, em parceria com o Fundo das Nações Unidas para a Infância (Unicef), desenvolveu uma investigação para compreender o aumento das taxas de homicidios de jovens de forma representativa. Esse estudo é um recorte desta pesquisa, mas tem como pontos específicos a segurança e o acesso institucional das familias com vitimas de adolescentes assassinados. O CCPHA buscou contatar todas as familias de crianças e adolescentes (de 0 a 19 anos) assassinados no ano de 2015 nas sete cidades cearenses com mais ocorrências (Fortaleza, Sobral, Juazeiro do Norte, Caucaia, Maracanaú, Horizonte e Eusébio). Assim, em 2016 foram entrevistadas todas as familias cujo contado foi possivel e que concordaram em participar da pesquisa. Todos os requisitos éticos foram atendidos, com o esclarecimento dos objetivos e metodologia da pesquisa e comprovado o aceite por meio da assinatura do Termo de Consentimento Livre e Esclarecido (TCLE), tendo sido submetido e aprovado pelo Comitê de Ética da Universidade Federal do Ceará (CAAE: 88857718.9.0000.5054). A aplicação dos questionários ocorreu por meio de entrevistas realizadas pela equipe técnica do CCPHA de forma individual nas casas dos familiares dos adolescentes.

\section{Análises}

Para alcançar o objetivo do estudo, foi construído um Índice de Pobreza Multidimensional (IPM) variando de o a 1, em que, quanto mais próximo a 1, maior é a situação de privação a partir da metodologia dos conjuntos fuzzy. Assim, a mensuração da pobreza ocorre a partir de gradações, diferenciando-se do método cripset (Chiappero-Martinetti, 2000; Lelli, 2001). Para a realização das análises comparativas, foi estabelecido um critério de criação dos grupos 
em situação de maior ou menor privação a partir do IPM superior ou igual à mediana empírica de 0,50 (Pasquali, 2003). Então, foram realizadas análises descritivas de frequência das respostas relativas à segurança territorial e institucional; e testes qui-quadrados para comparar os grupos com mais e menos pobreza multidimensional a partir do IPM quanto aos fatores que representam perigo no bairro, à confiança nas instituições e ao acesso a instituições após a morte do adolescente. Além disso, foi feita uma ANOVA para comparar a percepção da presença policial como fator de segurança no bairro para os grupos com maior e menor IPM. O índice de significância utilizado nas análises foi o padrão de 0,05 (Bisquerra, Sarriera, \& Martínez, 2004).

\section{Resultados e discussão}

\section{Relações institucionais}

No que se refere à relação das familias dos adolescentes com diferentes instituições, a Tabela 1 apresenta a confiança em instituições formais e informais. Em geral, as instituições mais pontuadas como confiáveis foram as religiosas $(80,2 \%)$, a familia $(78,7 \%)$ e a escola $(67,1 \%)$. Já as menos indicadas foram os programas de rádio e televisão (26,7\%), a justiça (23,6\%), a polícia (21,3\%) e amigos (18,2\%). Quanto à comparação entre os grupos mais e menos pobres, há uma diferença significativa da confiança na vizinhança $\left(\chi^{2}=7,26 ; p<0,01\right)$, nos amigos $\left(\chi^{2}=5,22 ; p<0,05\right)$ e, destacadamente, na policia $\left(\chi^{2}=30,36 ; p<0,001\right)$ a partir do teste qui-quadrado.

TABELA 1 - Frequências e qui-quadrados comparando a confiança nas instituições segundo grupos IPM.

\begin{tabular}{|c|c|c|c|c|}
\hline & Total & Maior pobreza & Menor pobreza & $\chi^{2}$ \\
\hline Justiça & $23,6 \%$ & $20,9 \%$ & $29,4 \%$ & 2,08 \\
\hline Vizinhança & $29,8 \%$ & $21,8 \%$ & $38,5 \%$ & $7,26^{* *}$ \\
\hline Amigos & $18,2 \%$ & $12,7 \%$ & $24,8 \%$ & $5,22^{\star \star \star}$ \\
\hline Conselho Tutelar & $40,3 \%$ & $34,5 \%$ & $46,8 \%$ & 3,40 \\
\hline Instituições religiosas & $80,2 \%$ & $77,3 \%$ & $84,4 \%$ & 1,79 \\
\hline Policia & $21,3 \%$ & $7,3 \%$ & $38,5 \%$ & $30,36^{*}$ \\
\hline Escola & $67,1 \%$ & $65.5 \%$ & $72,5 \%$ & 1,26 \\
\hline Programas de rádio e televisão & $26,7 \%$ & $31,8 \%$ & $23.9 \%$ & 1,72 \\
\hline Familia & $78,7 \%$ & $74.5 \%$ & $83.5 \%$ & 2,64 \\
\hline Nenhuma & $3.1 \%$ & $4,5 \%$ & $0,9 \%$ & 2,70 \\
\hline
\end{tabular}

Nota: ${ }^{* * *} p<0,05 ;{ }^{* *} p<0,01 ;{ }^{*} p<0,001$

São os sujeitos em maior situação de pobreza, e, portanto, o grupo que mais precisa acessá-las, que menos confiam nas instituições públicas. Dessa forma, a dinâmica da violência territorial que assola os moradores dos bairros mais pobres estimula a sensação de medo e insegurança, influenciando, principalmente, a fragilização dos vínculos sociais, visto que os dados apontam que nem mesmo amigos e vizinhos apresentamse como figuras confiáveis para os indivíduos inseridos nesse contexto. Pode-se refletir sobre a pouca confiança nessas relações tomando como base as problematizações levantadas por Bezerra e Carvalho (2015) acerca de um "viver acuado" nas margens urbanas. Segundo as autoras, o medo e a insegurança social são potencializados por dinâmicas de hiperindividualizaçãodescoletivização, deteriorização do espaço público, perdas significativas de referenciais sociais e fragilização e dissolução dos vínculos sociais. Essas experiências de insegurança e medos sociais relacionam-se também com os próprios modos 
de habitar a cidade, marcados pela desigualdade, hierarquização e segregação nos espaços urbanos.

A pouca relação de confiança dos mais pobres em relação às diversas instituições (justiça, conselho, polícia, escola etc.) demonstra, justamente, a condição de cidadania escassa, subcidadania ou mesmo não cidadania a que estão submetidos (Sales, 2007). A partir do diálogo com Achille Mbembe (2017) e Judith Butler (2015), Barros et al. (2018) apontam que a precarização induzida e maximizada das condições de vida de um amplo espectro de adolescentes negros e pobres, bem como de suas familias, corolário do abandono institucional e das desigualdades sociais já aludidas, também são dispositivos pelos quais opera a necropolítica cotidianamente nas periferias brasileiras.

Mbembe (2017) elabora a noção de necropolítica para se referir a uma tecnologia de poder que opera pela aniquilação do inimigo e denomina de colônia uma espécie de zona de morte onde se exerce um poder à margem da lei e na qual guerra e paz não se distinguem. As práticas do estado de exceção se dirigem aos habitantes das margens urbanas, figurando-os como elementos suspeitos e potencialmente perigosos, de modo a prevalecer sobre eles a vigilância, o controle e a punição. Essa desconfiança no Estado e mesmo entre vizinhos mostra como estado de exceção e relação de inimizade, segundo Mbembe (2016), constituem a base normativa do direito de matar certos grupos populacionais, produzindo, mediante processos de racialização, corpos viviveis e corpos matáveis, subjetividades acuadas pelo medo, demandantes de segurança em detrimento de liberdade, e existências abjetas.

Apesar de os amigos terem apresentado a menor frequência de confiança entre as instituições quando considerada a amostra total, foi a polícia que se destacou na comparação dos grupos em maior e menor condição de pobreza. Apenas 7,3\% dos mais pobres apontaram a policia como uma instituição confiável, ao passo que $38,5 \%$ dos menos pobres o fizeram. Dessa forma, fica nitida a relação conflituosa dos mais pobres com a policia, sendo essa a relação institucional de confiança mais afetada pela condição de privação. Observa-se que há um crescimento de assassinatos realizados pela polícia, podendo afetar esse sentimento de não confiança nessa instituição (Cerqueira et al., 2017). O fato de os mais pobres terem uma visão negativa sobre a polícia, apresenta-se como um reflexo da seletividade e da violação de direitos básicos que caracteriza historicamente a atuação da policia nos bairros periféricos, pode corroborar com o ponto de vista defendido por autores como Zaccone (2015), segundo os quais a guerra às drogas, que norteia a política de segurança atual, revela-se como uma "guerra aos pobres", vistos cada vez mais como inimigos internos. Essa pouca confiança, então, surge como fruto da própria política de segurança pública que elege um inimigo que direciona as suas práticas ao combate do mesmo.

Por fim, quanto ao acesso institucional após a morte do adolescente, conforme a Tabela 2, menos de $10 \%$ das familias afirmaram ter procurado organizações da sociedade civil, ministério público, juizado da infância e da juventude, conselho tutelar e defensoria pública. As instituições mais acessadas foram hospital (20,9\%), delegacia de policia $(53,2 \%)$ e instituto médico legal $(72,6 \%)$. As pessoas em maior situação de pobreza tiveram menos acesso a todas as instituições, mas de maneira mais significativa ao hospital $\left(x^{2}=11,77\right.$; $\mathrm{p}<0,01)$ a partir do teste qui-quadrado. 
TABELA 2 - Frequências e qui-quadrados comparando acesso a instituições após a morte do adolescente por grupos IPM.

\begin{tabular}{lcccc}
\hline & Total & Maior pobreza & Menor pobreza & $\chi^{\mathbf{2}}$ \\
\hline Conselho Tutelar & $5,7 \%$ & $3,6 \%$ & $6,4 \%$ & 3,57 \\
Delegacia de Polícia & $53,2 \%$ & $50,0 \%$ & $61,5 \%$ & 5,11 \\
Defensoria Pública & $8,4 \%$ & $6,4 \%$ & $8,3 \%$ & 0,00 \\
Juizado da Infância e da Juventude & $4,2 \%$ & $3,6 \%$ & $3,7 \%$ & 5,11 \\
Ministério Público & $3,6 \%$ & $0,9 \%$ & $5,5 \%$ & 2,07 \\
Organização da Sociedade Civil & $3,0 \%$ & $0,9 \%$ & $3,7 \%$ & $11,77^{* *}$ \\
Hospital & $20,9 \%$ & $12,7 \%$ & $27,5 \%$ & 1,26 \\
\hline
\end{tabular}

Nota: ${ }^{* *} \mathrm{p}<0,01$

Os dados indicam que as familias com mais intensa situação de pobreza têm menos acesso aos serviços. Além disso, de acordo com Freitas e Guareschi (2014), a política pública para pessoas em situação de pobreza geralmente é desenvolvida com uma menos qualidade por conta do processo de estigmatização. Decorrente disso, podem ser desenvolvidos preconceitos pelos profissionais em razão da crença de que as pessoas inseridas nessa situação são criminosas e culpadas pela sua situação (Moura Jr. \& Ximenes, 2016). Assim, estabelece-se um ciclo de exclusão, pois justamente aqueles que mais necessitam de políticas púbicas de qualidade têm esse acesso mitigado. Isso pode ocorrer, porque as instituições que deveriam acolher essa população podem reproduzir visões estigmatizadas das pessoas em situação de pobreza (Freitas \& Guareschi, 2014). As familias, provavelmente, expostas a um histórico de desigualdades e de violências que culminaram no assassinato de um jovem, têm intensificado os seus sofrimentos pela ausência da garantia de direitos, como o suporte institucional após a morte do adolescente.

Implicações da condição de pobreza nas percepções sobre segurança territorial

A maior parte das familias de adolescentes vitimados por homicídio está em situação de pobreza. Apesar disso, existem aqueles mais e menos expostos a privações. Mesmo dentro desse grupo, existem diferenças em como uma maior situação de pobreza afeta à percepção de familiares sobre segurança territorial. Podemos ver, de acordo com os dados da Tabela 3 . que $85,4 \%$ das familias que responderam ao questionário consideram como perigosos os bairros onde moram. Quanto aos fatores que representam perigo para as familias nos bairros, o tráfico de drogas aparece como o principal causador da insegurança $(46,7 \%)$, seguido de assaltos e roubos (34,5\%), tiroteios (27,6\%), assassinatos $(20,7 \%)$ e batidas policiais $(10,3 \%)$.

Os dados indicam que a vivência das famílias em relação aos seus bairros é atravessada pela sensação de insegurança e pelo medo. Essa sensação de insegurança opera na produção de modos específicos de ocupação do espaço urbano pela população. Como afirma Felix (2009, p. 156), "o medo de ser vítima condiciona o nível de exposição ao risco". Isso significa que se desenvolvem estratégias como evitar andar com pertences de valor, evitar ao máximo passar por determinados locais, evitar sair de casa à noite etc. Além disso, dialogando com Barros, Paiva, 
Rodrigues, Leonardo e Silva (2018), a percepção de que o tráfico de drogas aparece como o fator que causa maior insegurança nos moradores desses bairros tem sido potencializada a partir de transformações da dinâmica do crime em comparação com os cenários existentes nas décadas de 1990 e 2000. Nesse período, o tráfico de drogas se fortaleceu e faccionalizou, sedimentando e ampliando controles da vida e da morte em territorialidades periféricas urbanas, cujos cotidianos encontram-se sob o domínio de grupos criminosos.

TABELA 3 - Frequências e qui-quadrados dos fatores que representam perigo no bairro para grupos IPM.

\begin{tabular}{lcccc}
\hline & Total & Maior pobreza & Menor pobreza & $\chi^{2}$ \\
\hline Considero Perigoso & $85,4 \%$ & $82,6 \%$ & $89,0 \%$ & 1,84 \\
Tiroteios & $27,6 \%$ & $25,7 \%$ & $24,8 \%$ & 0,02 \\
Assaltos e roubos & $34,5 \%$ & $31,2 \%$ & $34,9 \%$ & 0,33 \\
Tráfico de drogas & $46,7 \%$ & $50,5 \%$ & $41,3 \%$ & 1,84 \\
Assassinatos & $20,7 \%$ & $22,9 \%$ & $13,8 \%$ & 3,06 \\
Batidas policiais & $10,3 \%$ & $13,8 \%$ & $4,6 \%$ & $5,50^{* *}$ \\
\hline
\end{tabular}

Nota: ${ }^{* *} p<0,01$

Podemos, ainda, destacar uma maior preocupação do grupo menos pobre com assaltos e roubos (34,9\%) do que o mais pobre (31,2\%). Já o grupo mais pobre, tem maior preocupação com o tráfico (50,5\%), os assassinatos (22,9\%) e, sobretudo, as batidas policiais (13,8\%). Esses dados apontam para uma preocupação maior por parte do grupo mais pobre relativa a aspectos da violência contra a vida, enquanto o grupo menos pobre tende a preocupar-se mais com crimes contra o patrimônio. Há um medo mais evidente vinculado a assaltos nas pessoas que têm maior poder aquisitivo, mas o medo de ser assassinado ocorre com maior prevalência nas pessoas com maiores niveis de pobreza (Lavor Filho et al., 2018). Essa preocupação maior, relativa aos crimes contra a vida por parte do grupo mais pobre, relaciona-se com fatores como a atuação seletiva das forças de segurança, como afirmam Machado e Noronha (2002), assentadas no discurso de "combater a criminalidade", muitas vezes legitimado por parte da população que vê na repressão a única alternativa de resolução da problemática da violência urbana. Outro fator é a dinâmica da atuação do crime organizado dentro das favelas, dinâmica essa fortemente marcada por práticas extremamente violentas que envolvem disputas entre facções criminosas rivais e que frequentemente acabam por afetar não só aqueles envolvidos nos conflitos, mas os moradores de tais territórios em geral, deixando-os particularmente suscetiveis à atuação violenta desses grupos.

Em relação ao ponto "batidas policiais", é possivel apontar que há uma relação significativamente diferente entre os dois grupos $\left(\chi^{2}=5,50 ; p<0,01\right)$ por meio da análise do qui-quadrado. A presença ostensiva da polícia nos bairros mais pobres está fortemente ligada à "gestão da pobreza" de um Estado que se configura como Estado penal. Wacquant (2003) mostra como, no contexto americano, o governo dos Estados Unidos respondeu à crescente dos problemas sociais (pobreza, violência, desemprego etc) por meio da repressão policial. É possivel traçar um paralelo com o contexto brasileiro, à medida em que observamos que a repressão policial talvez seja a principal política pública, sendo, em alguns casos, a única a chegar cotidianamente em bairros da periferia. Partindo dessa diferença 
de percepção entre os grupos "mais pobres" e "menos pobres", é possivel conjecturar que essa atuação mais constante da polícia nos bairros mais pobres se dá devido à relação histórica que existe no imaginário popular entre "pobreza" e "crime" (Moura Jr. \& Ximenes, 2016), bem como devido à atuação das facções criminosas dentro das favelas (Barros et al., 2018).

Essa discriminação é constituida a partir de marcadores cuja presença equaliza a produção da concepção de uma existência segura a qual precisa da ideia de existência de perigo. É a intersecção da criminalização da pobreza (Moura Jr. \& Ximenes, 2016), do racismo estrutural (Almeida, 2018) e do reconhecimento do jovem como perigoso (Barros et al., 2018). É a partir dessa encruzilhada de matrizes de dominação que são geradas essas identidades interseccionais que sintetizam e singularizam opressões (Henning, 2015). Assim, o indivíduo é considerado "perigoso" não por seus atos concretos, mas por seu "perigo potencial". O fetichismo da segurança, nas palavras Wacquant (2003), reverberado como mantra da ideologia neoliberal serve como esteio para acirrar o oximoro Cidadão de bem/ bandido. Nessa lógica o primeiro deve ter a sua existência assegurada e protegida de qualquer interferência ou ameaça externa, enquanto o segundo é a materialização dessa interferência e dessa ameaça e como tal deverá ser eliminado.

Esse cenário de "guerra" nas periferias figura, para as e os participantes do estudo, entre os principais motivos da violência nos bairros em que vivem. Como pode ser visto na Tabela 4, 89,1\% consideram a localidade em que moram violenta, sendo o tráfico de drogas a causa mais apontada pelas famílias (52,3\%), seguido dos conflitos entre gangues (14,4\%). As famílias em menor situação de pobreza indicaram com maior frequência em ambos os casos, respectivamente, 56,2\% e $21 \%$. Segundo Barros et al. (2018), há processos de territorialização marcados por situações de violência que perpassam as relações sociais e dificultam o trânsito dentro do próprio bairro. Há pessoas que integram grupos que disputam o território, participando de sistemas de vingança entre eles, e outras que poderão ser atingidas pela violência apenas por morarem em lugares que são alvo do conflito, o que engendra uma série de cuidados na entrada e saída desses locais.

TABELA 4 - Frequências e qui-quadrados dos motivos da violência no bairro para grupos IPM.

\begin{tabular}{|c|c|c|c|c|}
\hline & Total & Maior pobreza & Menor pobreza & $\chi^{2}$ \\
\hline Considero violento & $89,1 \%$ & $88,0 \%$ & $90,5 \%$ & 1,84 \\
\hline Tráfico de drogas & $52,3 \%$ & $46,3 \%$ & $56,2 \%$ & 2,08 \\
\hline Conflito entre gangues & $14,5 \%$ & $12,0 \%$ & $21,0 \%$ & 3,08 \\
\hline Conflito entre territórios & $5,1 \%$ & $5,6 \%$ & $3,8 \%$ & 0,36 \\
\hline Conflitos com agentes públicos & $2,3 \%$ & $3.7 \%$ & $1,9 \%$ & 0,62 \\
\hline
\end{tabular}

Por fim, sobre a percepção da postura da polícia nos bairros pelas familias, na Tabela 5 . pode-se ver que há uma diferença significativa na relação dos mais pobres e dos menos pobres $(F=34,487 ; p<0,001)$ por meio de Análise de Variância (ANOVA). Enquanto para o grupo mais pobre a presença policial é intimidadora $(39,1 \%)$ ou indiferente $(49,1 \%)$, para o grupo menos pobre essa presença é considerada protetora $(38,5 \%)$ ou indiferente (48,6\%). Apesar de parte dos respondentes ter indicado a presença da polícia como algo indiferente à segurança, muitos indicaram essa presença como intimidadora ou como protetora. Dentre aqueles que indicaram a presença da polícia como intimidadora ou protetora, o pertencimento ao grupo de maior 
ou menor pobreza foi determinante, pois os participantes pertencentes ao grupo de menor pobreza tenderam a percebê-la como protetora e os pertencentes ao grupo de maior pobreza tenderam a percebê-la como intimidadora. Isso ocorre, porque os casos de assassinato por policiais têm crescido no Brasil (Cerqueira et al., 2017, 2018), gerando um sentimento de medo nos mais pobres que são aqueles que mais morrem no País (Melo \& Cano, 2017).

Essas percepções diferentes em relação à postura da polícia ratificam a seletividade que perpassa a atuação dos agentes de segurança pública. O estereótipo do criminoso - que guia a ação da polícia, dos promotores, dos juizes e domina a opinião pública e os meios de informação em massa - corresponde às caracteristicas dos grupos sociais entre os quais o sistema seleciona e recruta os seus clientes reais entre todos os potenciais (Baratta, 2003). Dessa forma, entendemos que essa percepção de uma atuação policial intimidadora por parte do grupo mais pobre é apenas o reflexo do que pode ser considerado historicamente como o modus operandi do Estado penal-policial nas periferias: a repressão violenta dos marginalizados pela justificativa da segurança pública.

TABELA 5 - Frequências e ANOVA comparando grupos IPM em relação à percepção da presença policial como fator de segurança no bairro.

\begin{tabular}{cccc} 
& Protetora & Intimidadora & Indiferente \\
\hline Total & $24,5 \%$ & $25,7 \%$ & $49,8 \%$ \\
Maior pobreza & $11,8 \%$ & $39,1 \%$ & $49,1 \%$ \\
Menor pobreza & $38,5 \%$ & $12,8 \%$ & $48,6 \%$ \\
Comparação dos Grupos & & $\mathrm{F}=34,487^{*}$ & \\
\hline
\end{tabular}

Nota: " $p<0,001$

Para Zaccone (2015), um dos maiores legados da ditadura no Brasil é o que ele chama de "legalidade autoritária". Esse discurso de "luta contra o inimigo", característico da época da ditadura, continua presente nos operadores do sistema de justiça brasileiro, tendo a diferença fundamental da reconstrução da figura do inimigo, que na época da ditadura eram os "subversivos" contrários ao regime e hoje são os criminosos, os traficantes, inimigo elegido a partir da lógica da guerra às drogas. Sob essa justificativa, organizase um modelo de segurança pública baseado na repressão policial, fortemente atravessado por uma cultura militarizada, onde as regras são a intolerância com o crime e o extermínio do inimigo.

Nas favelas, os residentes estão encurralados entre o arbitrio dos traficantes, as incursões policiais (ou o domínio das localidades pelos "policiais pacificadores" que vêm a sucedê-las) e a profunda desconfiança da população da cidade que não mora nessas áreas (Silva, 2014, p. 18). Isso significa que, como afirmam Barros \& Benício (2017), esses residentes dos bairros mais pobres, que são mais afetados pelos aspectos da violência contra a vida, encontram-se em um perverso fogo cruzado: de um lado, são os mais vulneráveis à violência produzida pela dinâmica das atuações das facções criminosas e, por outro lado, são os mais expostos à violência institucional.

\section{Considerações finais}

Assim, observa-se que as implicações da condição de pobreza têm um impacto significativo na vida dessas familias que já estão em situação de sofrimento e violação por conta do assassinato de um jovem da familia. Observa-se um maior desamparo institucional, falta de acesso às políticas protetivas, atuação violenta da polícia e um território constituído de práticas de violência. Assim, há uma maior prevalência da sensação de 
insegurança que é inversamente proporcional à acentuação da condição de pobreza. Portanto, demonstra-se que os mais pobres são os mais afetados tanto pela atuação violenta dos grupos ligados ao tráfico de drogas como pelas práticas violadoras de direitos humanos características da atuação das forças de segurança.

Então, conclui-se que as familias mais pobres se encontram em uma condição crônica de abandono institucional, sendo esse um elemento importante para entender as condições de produção tanto da dinâmica dos homicídios quanto da situação de desamparo em que se encontram as famílias após tal evento. $\dot{E}$ desenvolvida uma espiral de violações e falta de amparo do Estado que tem gestado e gerenciado necropoliticamente a morte e a estigmatização da população mais pobre, jovem e negra e mantido violências institucionais e territoriais para as familias sobreviventes. Essa dinâmica aponta uma estratégia individualizante e criminalizadora das classes mais pobres representadas pelos adolescentes e suas familias.

As condições de pobreza acentuam as desigualdades e a vulnerabilização a diversas violências, sendo o homicidio o desfecho para alguns e, ao mesmo tempo, para os que ficam, a continuidade de uma vida onde a condição precária se encontra maximizada. Em coerência com recomendações elaboradas pelo CCPHA (Assembleia Legislativa do Estado do Ceará, 2017), os resultados do estudo, ao apontarem as diferenças nas relações institucionais e de segurança entre grupos em condições de maior ou menor pobreza, formados por familiares de jovens vítimas de violência letal, sugerem não só a urgência de ampliação de programas e projetos direcionados a segmentos infantojuvenis pauperizados, quanto a necessidade de responsabilização dos homicídios e um maior investimento em políticas públicas intersetoriais de proteção e apoio jurídico e psicossocial às familias vítimas de violência letal. Apontase como limitação a não utilização de escalas psicométricas, pois forneceriam uma maior validade aos dados encontrados. Igualmente, poderia ser interessante desenvolver um estudo longitudinal com essas familias para identificar a permanência dessas violações ao longo do tempo.

\section{Referências}

Accorssi, A., Scarparo, H., \& Guareschi, P. (2012). A naturalização da pobreza: reflexões sobre a formação do pensamento social. Psicologia \& Sociedade, 24(3), 536-546. https://doi.org/10.1590/S010271822012000300007

Alkire, S., \& Foster, J. (2011). Counting and multidimensional poverty measurement. Journal of Public Economics, 95(7), 476-487. https://doi.org/10.1016/j. jpubec0.2010.11.006

Almeida, S. (2018). O que é racismo estrutural? Letramento: Rio de Janeiro. (DOI INEXISTENTE)

Assembleia Legislativa do Estado do Ceará (2018). Cada Vida Importa - Relatório do segundo semestre de 2017 do Comitê Cearense pela Prevenção de Homicídios na Adolescência. Fortaleza, 2018. (DOI INEXISTENTE)

Assembleia Legislativa do Estado do Ceará (2017). Cada Vida Importa - Relatório final do Comitê Cearense pela Prevenção de Homicidios na Adolescência. Fortaleza, 2017. (DOI INEXISTENTE)

Avila, R. P., Bagolin, I. P., \& Comin, F. V. (2012). Heterogeneidade indivi- duais versus intensidade da pobreza em Porto Alegre - RS. Revista EconomiA, 13(2), 447-463. Recuperado de http://www.anpec.org. br/revista/ vol13/vol13n2p447_463.pdf DOI INEXISTENTE)

Baratta, A. (2003). Principios do direito penal mínimo. Para uma Teoria dos Direitos Humanos como Objeto e Limite da Lei Penal. Florianópolis: Mimeo. (DOI INEXISTENTE)

Barros, J. P. P., \& de Souza Benicio, L. F. (2017). "Eles nascem para morrer": uma análise psicossocial da problemática dos homicídios de jovens em Fortaleza. Revista de Psicologia, 8(2), 34-43. (DOI INEXISTENTE)

Barros, J. P. P., Paiva, L. F. S., Rodrigues, J. S., Silva, D. B. \& Leonardo, C. S. (2018). "Pacificação" nas periferias: discursos sobre as violências e o cotidiano de juventudes em Fortaleza. Revista de Psicologia, 9(1), 117-128. (DOI INEXISTENTE)

Bezerra, L. M. P. S., \& Carvalho, A. M. P. (2015). Medo e insegurança nas margens urbanas: uma interpretação do "viver acuado" em territórios estigmatizados do Grande Bom Jardim. O público e o privado, 1(26). (DOI INEXISTENTE)

Bisquera, R., Sarriera, J. C., \& Martínez, F. (2004). Introdução à esta- tística: enfoque informático com o pacote estatistico spss. Porto Alegre: ArtMed

Butler, J. (2015). Quadros de guerra: quando a vida é passivel de luto. Rio de Janeiro: Civilização Brasileira. (DOI INEXISTENTE) 
Cerqueira, D. R. C., Ferreira, H., Lima, R. S. D., Bueno, S., Hanashiro, O., Batista, F., \& Nicolato, P. (2017). Nota técnica - Atlas da Violência 2017. Brasilia: FBSP/Ipea. (DOI INEXISTENTE)

Cerqueira, D. R. C., Ferreira, H., Lima, R. S. D., Bueno, S., Hanashiro, O., Batista, F., \& Nicolato, P. (2018). Nota técnica - Atlas da Violência 2018. Brasilia: FBSP/Ipea. (DOI INEXISTENTE)

Chiappero-Martinetti, E. (2000). A multidimensional assessment of well- -being based on Sen's functioning approach. Rivista Internazionale di Scienze Sociali, 2, 207-239. doi: 10.2307/41634742

Coimbra, C. M. B. (2001). Operação Rio: o mito das classes perigosas - um estudo sobre a violência urbana, a midia impressa e os discursos de segurança pública. Rio de Janeiro: Oficina do Autor. (DOI INEXISTENTE)

Damásio, B.F. (2013). Contribuições da Análise Fatorial Confirmatória Multigrupo (AFCMG) na avaliação de invariância de instrumentos psicométricos. Psico-USF, 18(2), 211-220. https://doi.org/10.1590/ S1413-82712013000200005

Felix, S. A. (2009). Crime, medo e percepções de insegurança. Perspectivas: Revista de Ciências Sociais, 36, 155-173. (DOI INEXISTENTE)

Feres, J. C., \& Villatoro, P. (2013). A viabilidade de se erradicar a pobreza: uma análise conceitual e metodológica. Cadernos de Estudos Desenvolvimento Social em Debate, 15, 10-87.

Freitas, C. R., \& Guareschi, P. A. (2014). A Assistência Social no Brasil e os usuários: possibilidades e contradições. Diálogo, (25), 145-160. (DOI INEXISTENTE)

Henning, C. E. (2015). Interseccionalidade e pensamento feminista: as contribuições históricas e os debates contemporâneos acerca do entrelaçamento de marcadores sociais da diferença. Mediações-Revista de Ciências Sociais, 20(2), 97-128. https://doi. org/10.5433/2176-6665.2015V20n2p97

Joly, M. C. R., Berberian, A. A., Andrade, R. G., \& Teixeira, T. C. (2010). Análise de teses e dissertações em avaliação psicológica disponiveis na BVS-PSI Brasil. Psicologia Ciência e Profissão, 30 (1), 174-187. https:// doi.org/10.1590/S1414-98932010000100013

Lavor Filho, T. L., Barbosa, V. N. M., Almeida Segundo, D. S., Moura Jr., J. F., Jannuzzi, P. M., \& Lima, R. S. (2018). Análises interseccionais a partir da raça e da classe: Medo do crime e autoritarismo no Brasil. Psicologia: Ciência e Profissão, 38(n.spe.2), 223-237. https://doi.org/10.1590/1982-3703000212376

Lelli, S. (2001). Factor analysis vs. Fuzzy sets theory: assessing the influence of different techniques on sen's functioning approach. Discussion Paper Series, Center for Economics Studies. Recuperado de http://econpapers.repec.org/paper/wpepapers/ ces0121.htm (DOI INEXISTENTE)

Machado, E. P., \& Noronha, C. V. (2002). A polícia dos pobres: violência policial em classes populares urbanas. Sociologias, 4(7), 188-221. https://doi. org/10.1590/S1517-45222002000100009
Mbembe, A. (2017). Politicas da Inimizade. Lisboa: Antígona. (DOI INEXISTENTE)

Mbembe, A. (2016). Necropolítica. Arte \& Ensaios. Rio de Janeiro: PPGAV, EBA, UFRJ, (32). (DOI INEXISTENTE)

Melo, D. L. B., \& Cano, I. (2017). Índice de homicidios na adolescência: IHA 2014. Rio de Janeiro: Observatório de Favelas. (DOI INEXISTENTE)

Moura Jr, J. F., Cidade, E. C., Ximenes, V. M., \& Sarriera, J. C. (2014). Concepções de pobreza: um convite à discussão psicossocial. Temas em Psicologia, 22(2), 341-352. https://doi.org/10.9788/TP2014.2-06

Moura Jr, J. F., \& Ximenes, V. M. (2016). A identidade social estigmatizada de pobre: uma constituição opressora. Fractal: Revista de Psicologia, 28(1), 76-83. https://doi.org/10.1590/1984-0292/1051

Pasquali, L. (2003). Psicometria: teoria dos testes na psicologia e na educação. Petrópolis: Vozes. (DOI INEXISTENTE)

Rego, W. D. L., \& Pinzani, A. (2013). Liberdade, dinheiro e autonomia. O caso da Bolsa Familia. Revista De Ciências Sociais-Politica \& Trabalho, 1(38), 21-42. (DOI INEXISTENTE)

Sales, M. A. (2007). (In)visibilidade perversa: Adolescentes infratores como metáfora da violência. São Paulo: Cortez.). Liberdade, dinheiro e autonomia. (DOI INEXISTENTE)

Scisleski, A.; Caetano, C. L. C.; Galeano, G. B. (2015). Pensando as (im) politicas para juventudes e os (in) direitos (des)humanos. In A. Scisleski, \& N. Guareschi (Orgs.), Juventude, marginalidade social e direitos humanos: da Psicologia às politicas públicas (pp. 167179). Porto Alegre: ediPUCRS. (DOI INEXISTENTE)

Sen, A. (2000). Desenvolvimento como liberdade. São Paulo: Companhia das Letras. (DOI INEXISTENTE)

Silva, L. A. M. (2014). Violência e ordem social. In: Lima, R. S.; Ratton, J. L.; Azevedo, R. G. Crime, policia e justiça no Brasil. São Paulo: Editora Contexto. (DOI INEXISTENTE)

Wacquant, L. (2003). Punir os pobres. A nova gestão da miséria nos Estados Unidos, v. 2. (DOI INEXISTENTE)

Wacquant, L. (2012). As prisões da miséria. 10 ed. Rio de Janeiro: Zahar. (DOI INEXISTENTE)

Ximenes, V. M., Moura Júnior, J. F., Cruz, J. M., Silva, L. B., \& Sarriera, J. C. (2016). Pobreza multidimensional e seus aspectos subjetivos em contextos rurais e urbanos nordestinos. Estudos de Psicologia, 21(2), 146156. https://doi.org/10.5935/1678-4669.20160015

Zaccone, O. (2015). Indignos de vida: a forma juridica da política de extermínio de inimigos na cidade do Rio de Janeiro. Rio de Janeiro: Revan. (DOI INEXISTENTE) 


\section{Endereço para correspondência}

João Paulo Pereira Barros (Avenida da Universidade 2799/2800, Fortaleza, Ceará, CEP 60020180; Telefone: (85) 33667722 / (85) 997343012, joaopaulobarros07@ gmail.com).

\section{Autor I}

Nome: João Paulo Pereira Barros.

Titulação Acadêmica: Doutor.

Afiliação Institucional: Universidade Federal do Ceará (UFC).

\section{Autor II}

Nome: James Ferreira Moura Júnior.

Titulação Acadêmica: Doutor.

Afiliação Institucional: Universidade da Integração Internacional da Lusofonia Afro-Brasileira (UNILAB)/ Universidade Federal do Ceará (UFC).

\section{Autor III}

Nome: Damião Soares de Almeida Segundo.

Titulação Acadêmica: Mestrando.

Afiliação Institucional: Universidade Federal do Ceará (UFC).

\section{Autor IV}

Nome: Rodrigo Bezerra Saraiva.

Titulação Acadêmica: Graduando.

Afiliação Institucional: Universidade Federal do Ceará (UFC).

\section{Autor V}

Nome: Marcus Giovani Ribeiro Moreira.

Titulação Acadêmica: Doutorando.

Afiliação Institucional: Universidade Federal do Ceará (UFC). 